\title{
PROPIEDADES FÍSICO-QUÍMICAS DE LOS SISTEMAS HIDROTERMALES ANDINOS
}

Leoncio Molina Vásquez ${ }^{1}$

\author{
R E S U M E N
}

Se realiza el análisis fisico-quimico de aguas geotermales situadas entre los volcanes Yucamani y Tutupaca de la provincia de Candarave, y del distrito de Ticaco en la provincia de Tarata del departamento de Tacna.

Estos resultados muestran el carácter sulfuroso y presencia de iones de Fe, Al, Na, K, As, etc., junto a la presencia de arqueobacterias que efectuan los mecanismos bioquímicos en medio ácido y temperaturas superiores al ambiente que las rodea.

El estudio de las fuentes geotermales es importante para determinar los iones y termodinamica de su transporte que producen las anomalias geoquimicas y comprender la contaminación natural en esa zona surandina. Las temperaturas elevadas sugieren una factibilidad de energia térmica a partir de ellas.

\section{A B S T R A C T}

The physical-chemical analysis of geothermical waters located between the Yucamani and Tutupaca volcanos has been performed. These volcanos belong to the province of Candarave and Ticaco in the province of Tarata - Tacna.

The results have shown that said volcanos are characterized by its sulphite content mainly and by the presence of archbacteria that make biochemical mechanisms in an acid environment and temperatures higher than the surrounding environment.

The study of geothermal sources is relevant in order to determine the ions and the thermo-dynamics of transport that produce the geochemical anomaly; and thus, being able to understand the natural contamination in the Southern area. The high temperatures suggest an availability of thermic energy from them.

\section{INTRODUCCIÓN}

Un campo geotermal puede definirse como un área térmica, donde la presencia de formaciones de roca permeable abajo del terreno, permiten el alojamiento de un fluido. El fluido de trabajo, agua o vapor o ambos asociados normalmente con ciertos gases, sirve como medio para la conducción del calor de asentamientos profundos hacia la superficie. Como los campos geotérmicos requieren tanto de agua como de calor para su existencia, se citan como sistemas hidrotermales.

Los campos geotérmicos pueden clasificarse en

tres tipos:

\section{Campos semitermales}

Capaces de producir agua caliente a temperaturas hasta $373,16 \mathrm{~K}$ desde profundidades de uno o dos $\mathrm{km}$.

\section{Campos húmedos}

Con producción de agua presurizada a temperaturas que exceden de $373,16 \mathrm{~K}$, en forma tal que cuando se lleva el fluido hasta la superficie y reduce su presión, una fracción se reduce a vapor en forma instantánea, mientras que la mayor parte se conserva como agua en ebullición.

\section{Campos secos}

Con la producción de vapor saturado seco o 
ligeramente sobrecalentado a presiones superiores a la atmosférica.

Una de las expectativas energéticas es la explotación geotérmica que históricamente tiene su máximo desarrollo tecnológico en Cerro Prieto México, alli se realizaron perforaciones muy similares a la explotación petrolera, obteniéndose agua a $623,16 \mathrm{~K}$, conducida a evaporadores, donde se capta vapor para las turbinas que producen energía eléctrica. El vapor condensado es transportado a reservorios, donde el agua se almacena para consumo humano y agrícola. La fase más densa, que contiene sales en solución es concentrada por destilaciones sucesivas hasta lograr obtener sustancias como litio cloruro ( $\mathrm{LiCl}$ ), magnesio, iodo, etc. Así, la región circundante de Cerro Prieto - México se transformó de una zona, pobre e inhóspita, con emanaciones sulfurosas, vapores y fuentes de aguas termales, en un territorio de promisorio desarrollo, con una industria, agricultura, ganaderia en desarrollo y abundante energía a bajo costo.

\section{TERRITORIO ANDINO DE TACNA}

Fuentes hidrotermales existen en toda la cordillera sur occidental de los Andes del Perú. Esta cordillera determina la orografia de las partes altoandinas que presentan una configuración muy sui géneris, porque ofrece una serie continua de montañas, cuyas cumbres forman crestas con fuerte declive hacia la costa. La zona serrana y la cordillera del Barroso forman una región central con una elevada faja de terreno altiplánico, que llega a tener más de $4100 \mathrm{msnm}$, donde se elevan colosales cerros, volcanes activos y apagados, cubiertos de nieve. En el limite sur se hallan el Huayhuasi, Payachatá, Coporatá, hacia el norte altiplánico se avistan otro grupo de imponentes picachos desafiantes, tales como el Sahama, Cara Cara, Queñuta, Pallagua, Yucamani y Tutupaca.

Esta zona la riegan varios rios que corren por quebradas profundas y nacen en la cordillera sur occidental andina y del Barroso. El Curibaya e llabaya forman el Locumba, el primero proviene de las filtraciones y del agua empleada por la central de energia eléctrica de Aricota de la laguna del mismo nombre, donde desembocan los riachuelos Totora y Callazas. El Totora nace de la lagunita de Quistuña, detrás del volcán Tutupaca y cuyos deshielos la forman, el segundo se origina directamente del Tutupaca y sigue su curso hasta unirse con el Totora.

El Sama se forma por la unión del Chaspaya y el
Estique, proviene de la cordillera del Barroso, recibiendo como afluente el Chacavira.

\section{ANOMALIAS EN AGUAS NATURALES}

Estas se conocen como anomalias hidrotermales. Los elementos que viajan, con facilidad en este tipo de agua y según los análisis químicos son $\mathrm{SO}_{4}^{2-}>\mathrm{Mo}>\mathrm{V}>\mathrm{Zn}>\mathrm{Cu}$. Estudios experimentales en Rusia han encontrado que la movilidad de otros elementos es en el orden: $\mathrm{Pb}, \mathrm{Cr}, \mathrm{Be}, \mathrm{Co}, \mathrm{Ni}, \mathrm{Sn}, \mathrm{W}$, $\mathrm{Ag}, \mathrm{Bi}, \mathrm{Sb}$ y $\mathrm{As}$. La presencia de sustancias orgánicas e inorgánicas en las aguas en forma soluble o como componente de una suspensión estable en fase móvil son:

\subsection{CATIONES}

La mayoria de los metales se presentan en agua geotermal como cationes, ejemplo:

$\mathrm{Zn}^{2+}$ y $\mathrm{Cu}^{2+}$. Una excepción es el uranio que es móvil como complejo $\mathrm{VO}_{2}^{2-}$. Algunos de los cationes solubles pueden ser medidos por pruebas calorimétricas, otros, por sus concentraciones muy bajas, requieren de una separación preliminar (cromatografía o coprecipitación).

\subsection{ANIONES}

Bajo determinadas condiciones los elementos no metálicos viajan en forma estable. En aguas oxidantes el $\mathrm{S}$ y Mo forman complejos de $\mathrm{SO}_{4}^{2-} \mathrm{y}$ $\mathrm{MoO}_{4}^{2-}$; el As y el Se en aguas naturales están probablemente presentes como aniones.

\subsection{IONES ABSORBIDOS SOBRE MATERIAL EN SUSPENSIÓN}

Se utilizan un grano pequeño y una gran superficie en el material suspendido para lograr una gran capacidad en el intercambio iónico. En este procedimiento existe un equilibrio activo sostenido entre los iones en solución y los iones absorbidos sobre las superficies del material en suspensión.

\subsection{MOLÉCULAS INORGÁNICAS NO-DISOCIADAS}

Son soluciones acuosas de moléculas no disociadas y no ionizadas. La sustancia mas importante es el silicio (IV) óxido, SiO2(Sílice) o cuarzo. La determinación de moléculas no disociadas requiere de la evaporación de la muestra y redisolución del residuo en un reactivo apropiado. 


\subsection{MATERIAL ORGÁNICO SOLUBLE}

Se forman al reaccionar los metales en su forma iónica con los compuestos orgánicos del humus, para formar compuestos órgano metálicos no disociados y solubles en agua. La determinación del metal retenido bajo esta forma, requiere normalmente evaporación de la muestra, seguida por la extracción con solventes, incineración u oxidación del residuo.

\subsection{SUSPENSOIDES}

La cantidad de elementos químicos que se movilizan en las aguas hidrotermales está en función de la presión, turbulencia, grano fino del cristal, actividad orgánica y de los factores que tienden a estabilizar las dispersiones coloidales de los hidróxidos de $\mathrm{Fe}, \mathrm{Mn}, \mathrm{Si}, \mathrm{Al}$. El contenido del material no - iónico en suspensión se determina por evaporación del agua y análisis del residuo.

La composición de los elementos en la fase móvil está condicionada por los conductos geoquímicos y la estabilidad de los componentes de las rocas.

\section{PRINCIPALES CAMPOS HIDROTERMALES ANDINOS DE TACNA}

\subsection{CAMPO GEOTERMAL DE CANDARAVE}

Ubicado en la provincia del mismo nombre, a más o menos $10 \mathrm{~km}$ de la localidad de Candarave, sobre la margen izquierdo del río Callazas, justamente en las faldas del volcán Yulcamani, se encuentra dos afloramientos de agua termal. Tienen las siguientes coordenadas $17^{\circ} 15,3^{\prime}$ latitud sur y $70^{\circ} 15,5^{\prime}$ longitud oeste.

- El agua emerge en terrenos aluviales que descansan sobre coladas volcánicas de naturaleza traquítica. Uno de los manantiales tiene obras civiles rústicas que sirve para bañarse. La temperatura de surgencia varia entre $44^{\circ} \mathrm{C}$ $(317,16 \mathrm{~K})$ y $47 \mathrm{oC}(320,16 \mathrm{~K})$, mientras que el otro manantial se halla al descubierto y registra temperaturas entre $42,7^{\circ} \mathrm{C}(315,7 \mathrm{~K})$ y $43,6^{\circ} \mathrm{C}$ $(316,6 \mathrm{~K})$.

\subsubsection{Características físico-químicas de las aguas hidrotermales de Candarave}

a) Localidad: Los Baños

b) Temperatura de la muestra: $44,2^{\circ} \mathrm{C}$ $(317,36 \mathrm{~K})$. c) $\mathrm{pH}$ ácido: $3,5-4,2$.

TABLA N 1: Gases en aguas hidrotermales. Los Baños, Candarave.

\begin{tabular}{|c|c|}
\hline SUSTANCIA & $\mathrm{g} \mathrm{dm}^{-3}$ \\
\hline $\mathrm{CO}_{2}$ & 0,005125 \\
$\mathrm{~N}_{2}$ & 0,008200 \\
$\mathrm{O}_{2}$ & 0,003075 \\
\hline
\end{tabular}

FUENTE: UNSA - Arequipa - 1980

TABLA № 2: Composición química. Los Baños, Candarave.

\begin{tabular}{|l|c|c|}
\hline SUSTANCIA & $\mathrm{g} \mathrm{dm}^{-3}(1)$ & $\mathrm{g} \mathrm{dm}^{-3}(2)$ \\
\hline $\mathrm{CaSO}_{4}$ & 0,2448 & 0,2573 \\
$\mathrm{MgSO}_{4}$ & 0,0810 & 0,0932 \\
$\mathrm{Na}_{2} \mathrm{SO}_{4}$ & 0,0241 & 0,0422 \\
$\mathrm{NaCl}$ & 2,4559 & 2,2986 \\
$\mathrm{SiO}_{2}$ & 0,1600 & 0,2206 \\
$\mathrm{Na}_{2} \mathrm{CO}_{3}$ & 0,8860 & 0,8342 \\
$\mathrm{Al}_{2} \mathrm{O}_{3}+\mathrm{Fe}_{2} \mathrm{O}_{3}$ & 0,013 & 0,0180 \\
$\mathrm{I}_{2}$ & Trazas & --- \\
\hline TOTAL & 3,3048 & 3,7741 \\
\hline
\end{tabular}

FUENTE: UNSA - Arequipa - 1980 (1), UNJBG - Tacna - 1991 (2).

\subsection{CAMPO GEOTERMAL DE CALIENTES}

En la cordillera sur occidental, localidad de Candarave, región eminentemente volcánica, denominada Calientes cuyas coordenadas son: $17^{\circ} 04,8^{\prime}$ latitud sur y $70^{\circ} 09,9^{\prime}$ longitud oeste. El liquido hidrotermal aparece en diferentes puntos a través de un derrame volcánico de naturaleza traquítica, entre temperaturas de $86,3^{\circ} \mathrm{C}$ $(359,46 \mathrm{~K})$ a $88,2^{\circ} \mathrm{C}(361,36 \mathrm{~K})$.

\subsubsection{Características físico - químicas del campo geotermal de Calientes.}

a) Localidad : Calientes

b) Temperatura de la muestra (2) : $87,1^{\circ} \mathrm{C}$ $(360,26 \mathrm{~K})$

c) $\mathrm{pH}$ ácido: $3,8-4,1$. 
TAB'BA N ${ }^{\circ}$ 3: Composición química. Calientes, Candarave.

\begin{tabular}{|l|l|l|}
\hline SUSTANCIA & $\mathrm{g} \mathrm{dm}^{-3}(1)$ & $\mathrm{g} \mathrm{dm}^{-3}(2)$ \\
\hline $\mathrm{CaSO}_{4}$ & 0,14960 & 0,15320 \\
$\mathrm{MgSO}_{4}$ & 0,01944 & 0,01840 \\
$\mathrm{Na}_{2} \mathrm{SO}_{4}$ & 0,16800 & 0,17130 \\
$\mathrm{NaCl}_{\mathrm{SiO}}$ & 0,59102 & 0,56210 \\
$\mathrm{Na}_{2} \mathrm{CO}_{3}$ & 0,14000 & 0,13630 \\
$\mathrm{Al}_{2} \mathrm{O}_{3}+\mathrm{Fe}_{2} \mathrm{O}_{3}$ & 0,04300 & 0,04080 \\
\hline $\mathrm{TOTAL}$ & 0,03000 & 0,03210 \\
\hline
\end{tabular}

FUENTE: UNSA - Arequipa - 1980 (1), UNJBG - Tacna - 1991 (2).

\subsection{TERMAS DE TICACO}

Ticaco está ubicado a unos $10 \mathrm{~km}$ al norte de la ciudad de Tarata, donde existe un manantial afluente del río Ticalaco, cuyas coordenadas son: $17^{\circ} 26,1^{\prime}$ latitud sur y $70^{\circ} 0,1^{\prime}$ longitud oeste. El agua surge en las faldas de un cerro constituido por roca intrusiva de naturaleza diorítica. El agua es transparente, algo salobre, sin olor y de gusto desagradable. Aparece con temperaturas entre $48,3^{\circ} \mathrm{C}(321,3 \mathrm{~K})$ y $49,8^{\circ} \mathrm{C}(322,8 \mathrm{~K})$.

\subsubsection{Caracteristicas físico - químicas de las termas de Ticaco.}
a) Localidad : Putina
b) Temperatura de muestra: $48,3^{\circ} \mathrm{C}(321,3 \mathrm{k})$
c) $\mathrm{pH}$ ácido: $5,5-6,2$.

TABLA N ${ }^{\circ}$ 4: Compuestos químicos. Putina - Ticaco.

\begin{tabular}{|l|c|c|}
\hline SUSTANCIA & $\mathrm{g} \mathrm{dm}^{3}(1)$ & $\mathrm{g} \mathrm{dm}^{3}(2)$ \\
\hline $\mathrm{CaCO}_{3}$ & 0,00800 & 0,01040 \\
$\mathrm{CaSO}_{4}$ & 0,55860 & 0,66130 \\
$\mathrm{MgSO}_{4}$ & 0,02280 & 0,02340 \\
$\mathrm{Na}_{2} \mathrm{SO}_{4}$ & 0,53880 & 0,53720 \\
$\mathrm{NaCl}$ & 0,60100 & 0,59430 \\
& & \\
$\mathrm{Al}_{2} \mathrm{O}_{3}+\mathrm{Fe}_{2} \mathrm{O}_{3}$ & 0,01400 & 0,01630 \\
$\mathrm{SiO}_{2}$ & 0,25000 & 0,28000 \\
\hline TOTAL & 1,76820 & 2,12290 \\
\hline
\end{tabular}

FUENTE: UNSA - Arequipa - 1980 (1), UNJBG - Tacna - 1991 (2).

\subsection{OTROS AFLORAMIENTOS HIDROTERMALES CONOCIDOS}

Dentro de ellos tenemos:

- Río Cono Tarata: $17^{\circ} 25,8^{\prime}$ latitud sur, $70^{\circ} 02,7^{\prime}$ longitud oeste.

- Aguas Calientes (volcán) Candarave:17³0,5' latitud sur. $69^{\circ} 50,2^{\prime}$ longitud oeste.

- Yabroco - Susapaya, provincia Tarata.

- Calientes - Pachía, provincia Tacna.

- Paucarani - Palca, provincia Tacna.

Fuentes hidrotermales que deben estudiarse.

Figura $\mathrm{N}^{\circ}$ 1: Ubicación de fuentes hidrotermales.

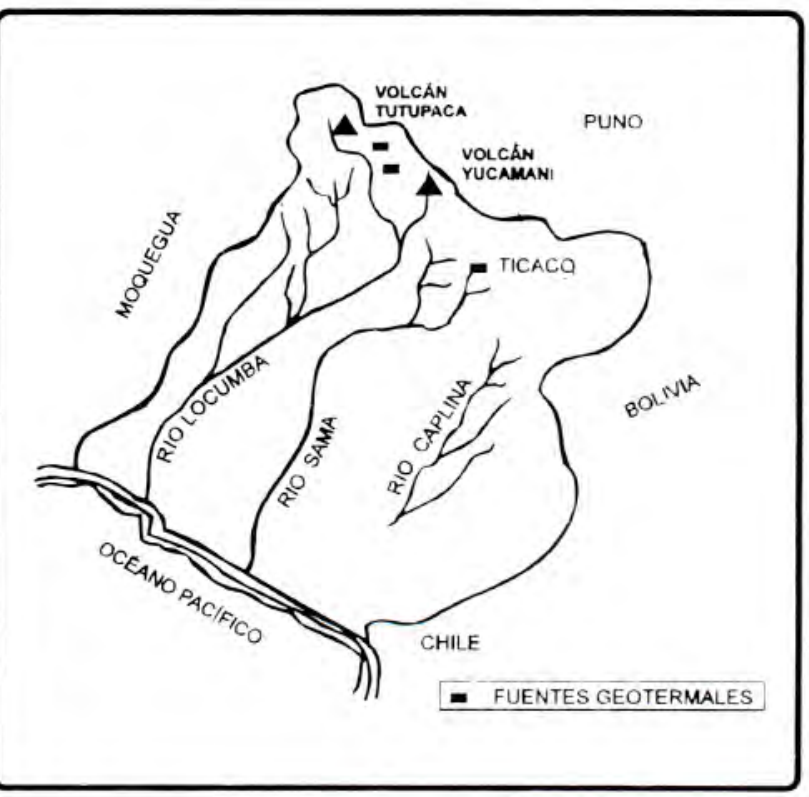

\section{DISCUSIÓN DE LOS RESULTADOS}

En las fuentes hidrotermales de Los Baños y Calientes de la provincia de Candarave se ha deteminado cualitativamente la presencia de archeobacterias, bacterias extremadamente termofilas, también llamadas dependientes del azufre identificados como sulfolobus, que utilizan azufre elemental como donador de electrones, los compuestos de azufre más comunes como fuentes de energia, son: hidrogeno sulfuro $\left(\mathrm{H}_{2} \mathrm{~S}\right)$ y azufre elemental $\left(\mathrm{S}^{\circ}\right)$. La oxidación final del azufre en la mayor parte de los casos es sulfato $\left(\mathrm{SO}_{4}^{2-}\right)$ que explica la presencia de estos aniones en el análisis realizado en las aguas hidrotermales. 


$$
\begin{array}{ccc}
\mathrm{H}_{2} \mathrm{~S}+2 \mathrm{O}_{2} & \cdots & \mathrm{SO}_{4(\text { aq) }}^{2-}+2 \mathrm{H}^{+}{ }_{(\text {aq) }} \\
\mathrm{S}^{\circ}+\mathrm{H}_{2} \mathrm{O}+3 / 2 \mathrm{O}_{2} & \cdots & \mathrm{SO}_{4(\text { aq })}^{2-}+2 \mathrm{H}^{+}{ }_{(\text {aq })}
\end{array}
$$

La oxidación del compuesto de azufre más reducido, $\mathrm{H}_{2} \mathrm{~S}$, se realiza en etapas y el primer paso en la oxidación da como resultado la formación del $\mathrm{S}^{\circ}$, una sustancia altamente insoluble. Algunas de las bacterias oxidantes del $\mathrm{H}_{2} \mathrm{~S}$ depositan el azufre elemental formado dentro de la célula. El azufre depositado como resultado de la oxidación inicial es una reserva de energía y cuando el suministro de $\mathrm{H}_{2} \mathrm{~S}$ se agota, se puede obtener energia adicional de la oxidación del azufre elemental depositado.

Nótese que en las reacciones de oxidación del azufre mostrados, arriba, uno de los productos es $\mathrm{H}+$. La producción de protones da como resultado el abatimiento del $\mathrm{pH}$ y uno de los resultados de la oxidación del azufre es la acidificación del medio. El ácido formado por las bacterias del azufre $\mathrm{es}_{2} \mathrm{SO}_{4}$;

\section{BIBLIOGRAFÍA}

BROCK, Madigan. Microbiología. Sexta edición Prentice Hall Hispanoamerica S.A. 1991 - México.

Christopher, An Mistead. Energía geotérmica 1ra. edición Noriega. Editores Limusa 1989 - México.

KAWKES - WEBB. Geochemistry in mineral exploration. las bacterias del azufre son capaces de alcanzar una marcada reducción del $\mathrm{pH}$ del medio.

En las mismas fuentes hidrotermales de Candarave se han identificado arqueobacterias halofilas identificadas como Halobacterium y Halococus que viven en un medio donde existen sulfatos en áreas calientes.

La presencia de bacterias litrotióficas se presupone porque los análisis nos proporcionan $\mathrm{Fe}_{2} \mathrm{O}_{3}$ que se produce en medio ácido como se aprecia en la reacción.

$$
2 \mathrm{Fe}^{2+}{ }_{\text {(aq) }}+1 / 2 \mathrm{O}_{2}+2 \mathrm{H}^{+}{ }_{\text {(aq) }}---->2 \mathrm{Fe}^{3+}{ }_{\text {(aq) }}+\mathrm{H}_{2} \mathrm{O}
$$

Que es una consumidora de protones.

La presencia del $\mathrm{CO}_{2}$ se explica porque existen arqueobacterias autotrofas que son capaces de obtener todo el carbono que necesitan de fuentes inorgánicas.
Traducción Lanckneus Jean. Ed. UNTAC 1980 - Perú. MOLINA, Leoncio. Energía geotermal en provincia de Tarata. Boletín Científico Año 2 Nº $^{\circ} 7$ setiembre 1980 - Perú.

TAMAYO, Lupe y otros. Energía Geotérmica en el Sur del Perú. Edit UNSA 1980 - Perú
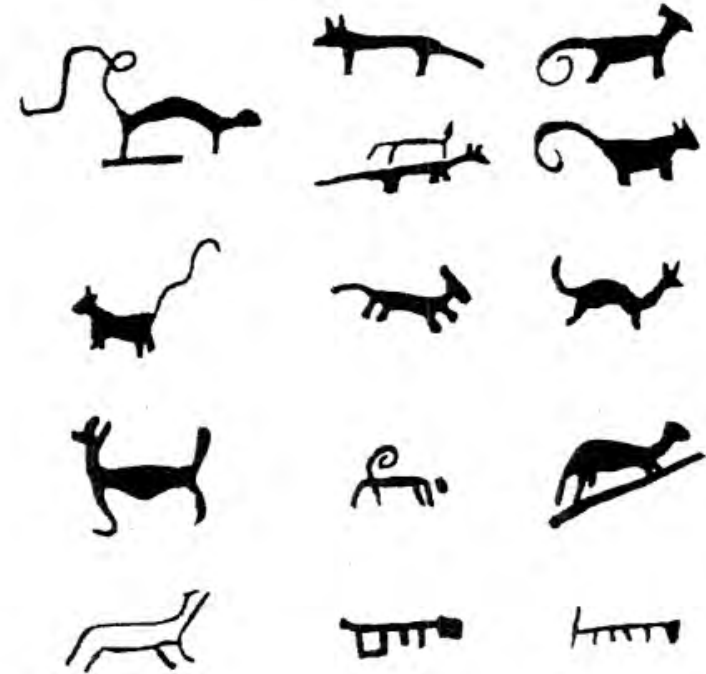

Fauna andina representativa: felino, zorro, perro, simio, otros no identificados. 